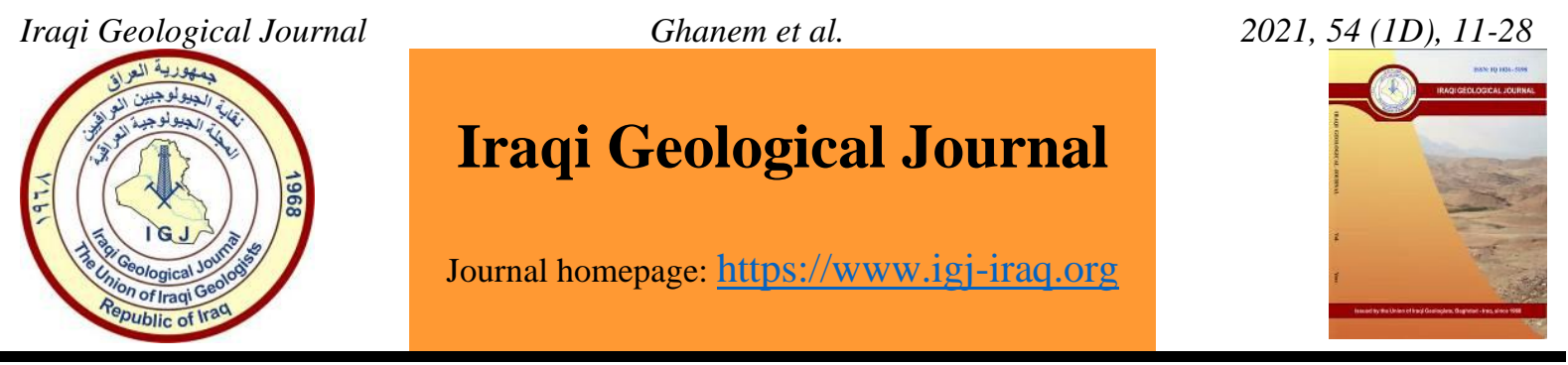

\title{
Geotechnical Engineering Evaluation of Superficial Deposits Utilizing Seismic Methods at Al al-Bayt University, Jordan
}

\author{
Fatima K. Ghanem ${ }^{1,}$, Hani Al Amoush', Eid Al-Tarazi \\ ${ }^{1}$ Department of Earth and Environmental, University of Al al-Bayt, Mafraq, Jordan \\ ${ }^{2}$ Department of Earth and Environmental Sciences, University of the Hashemite, Zarqa'a, Jordan \\ *Corresponding author: Ghanem.f2020@gmail.com
}

Received:23 November 2020; Accepted: 24 January 2021; Published : 30 April 2021

\begin{abstract}
Integration of seismic refraction tomography and multi-channel analyses shear wave methods were used at $\mathrm{Al}$ alBayt university campus in Mafraq, NE Jordan to delineate the shallow subsurface layering and determine their geotechnical properties, in addition, to estimate the geotechnical engineering parameters of the superficial deposits for detailed purposes. The P-wave refraction velocities were found to range from 180 to $2300 \mathrm{~m} / \mathrm{s}$ for the three identified layers which indicating superficial soil deposits with an increasing degree of compaction with depth. The S-wave velocities were found to lie in a narrow velocity range $(250$ to $600 \mathrm{~m} / \mathrm{s})$, which badly resolved the subsurface layering. Moreover, four soil samples were taken from the sites of seismic survey points for density calculations. The average calculated density was found to be $1.85 \mathrm{~g} / \mathrm{cm} 3$. Two soil samples from nearby seismic profile- 1 and seismic profile- 4 were tested for geotechnical properties. The results showed that the seismic method is an effective tool to estimate the different elastic moduli; Poisson's ratio, Young's modulus, Bulk modulus, Shear modulus, Lame's constants, and geotechnical engineering parameters; $\mathrm{N}$-value, bearing capacity, material index, concentration index, and stress ratio of the superficial soil deposits. The study recommends conducting a detailed geophysical study before starting any type of geoengineering construction in the area.
\end{abstract}

Keywords: Elastic moduli; Geotechnical parameters; Multi-channel analyses shear wave; seismic refraction tomography; superficial deposits

\section{Introduction}

Several geophysical methods have been suggested for engineering site studies, it was considered as progressively acceptable tools to give more information about the subsurface structures and lithology for seismologists and civil engineers (Benson and Yuhr, 2002; Goldstein, 1994; Benson et al. 1983; Al-Kubaisi and Shakir, 2018; Alsamarraie, 2020). The seismic methods are traditionally used in several exploration studies such as civil engineering and geotechnical studies to investigate the subsurface geological layering and many other purposes such as environmental, engineering, groundwater, industrial-mineral exploration, and hydrocarbon exploration (Khalil and Hanafy, 2008; Bridle, 2006; Hodgkinson and Brown, 2005). The seismic methods are attractive because of their costeffectiveness, fast field surveying and easy data processing and interpretation. The seismic refraction tomography (SRT) method is commonly used to detect the physical properties of the subsurface in order to mapping the horizontal and vertical variations of subsurface geological features and soil characterization in the site investigations (Al-Heety and Shanshal, 2016). The Multichannel-Analyses

DOI: $\underline{10.46717 / i g j .54 .1 D .2 M s-2021-04-22}$ 
Shear Wave (MASW) method is used in geotechnical studies to estimate shear velocity (Vs) of subsurface materials, the relation between (Vs) and depth, and other geotechnical parameters of soil. It is used commonly for shallow depths (Priya and Dodagoudar, 2017; Park, 2013). Several geophysical studies have been carried out to determine the layers of various seismic velocities and estimate engineering parameters in different parts of the world by seismic methods ( Abudeif et al. 2019; Srinivas et al. 2018; Al-Heety and Shanshal, 2016; Pegah and Liu, 2016; Al-Saigh and Al-Heety, 2013).

This study aims to investigate the subsurface geological layering and estimate the engineering parameters of the soil, it will enable us to determine if the various seismic techniques are efficient tools to describe near surface and superficial soil deposits. Moreover, it will also help us to estimate the different dynamic elastic properties of the soil layer which would be used for future engineering construction.

\section{Study Area}

Al-Bayt University campus is located in Al-Mafraq, NE-Jordan, it is bounded by 239119 $240402 \mathrm{E}$ and 3580967-3579482 N, (UTM coordinate system) (Fig. 1). The study area covers an area of about $2.68 \mathrm{~km}^{2}$ which is characterized by its relatively flat topography (Al-Ansari and Baban, 2001). Geologically, the Quaternary deposits are represented by superficial deposits (clayey silty sand) which almost covers Al-Mafraq, and consists mainly of two soil types: the red soil and the desert soil (Smadi, 1997; Gharaibeh, 2003).

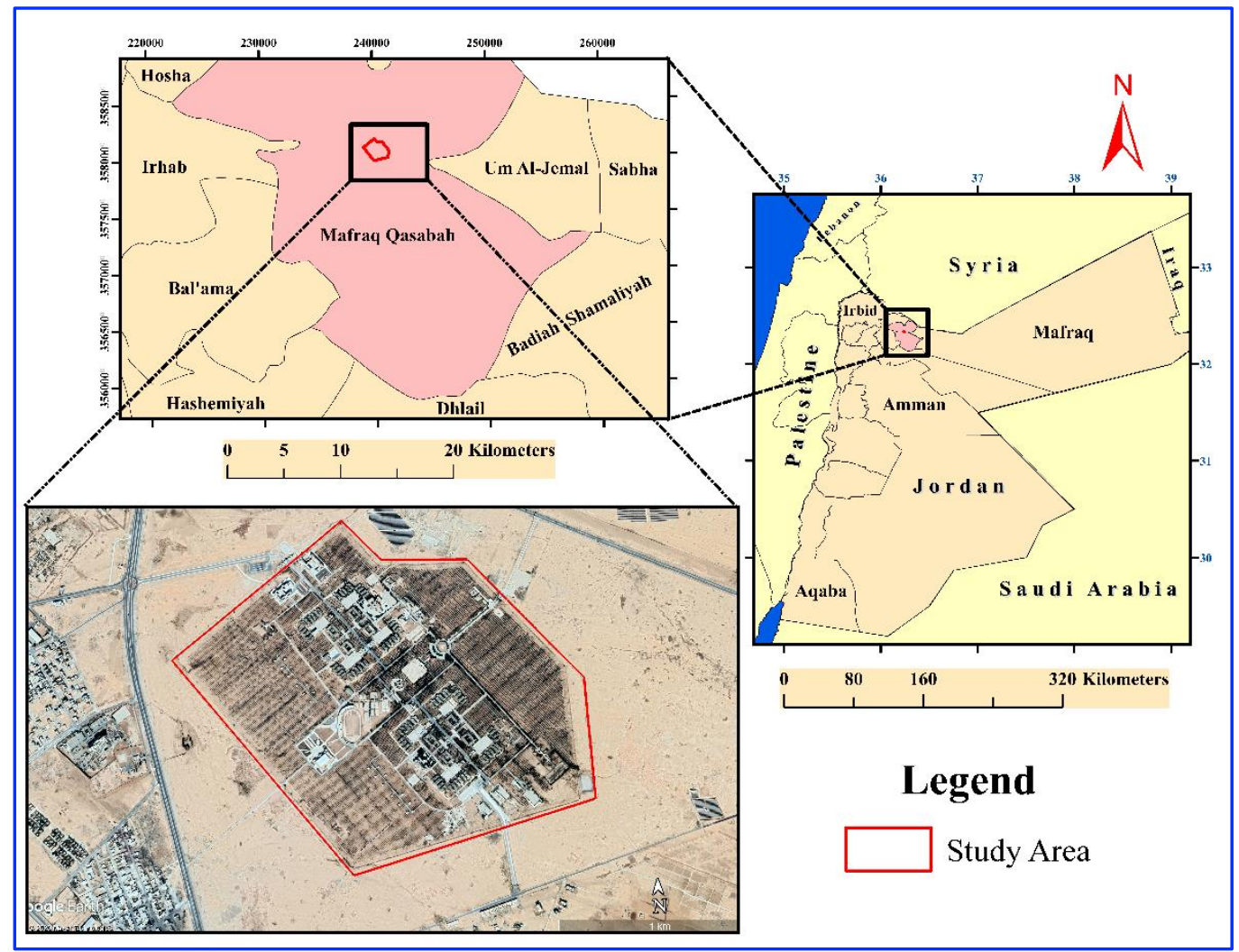

Fig. 1. Location map of the study area (Al al-Bayt university campus)

\section{Materials and Methods}

The adopted methodology to achieve the objectives of the present study is summarized in the flow chart shown in Fig. 2. 


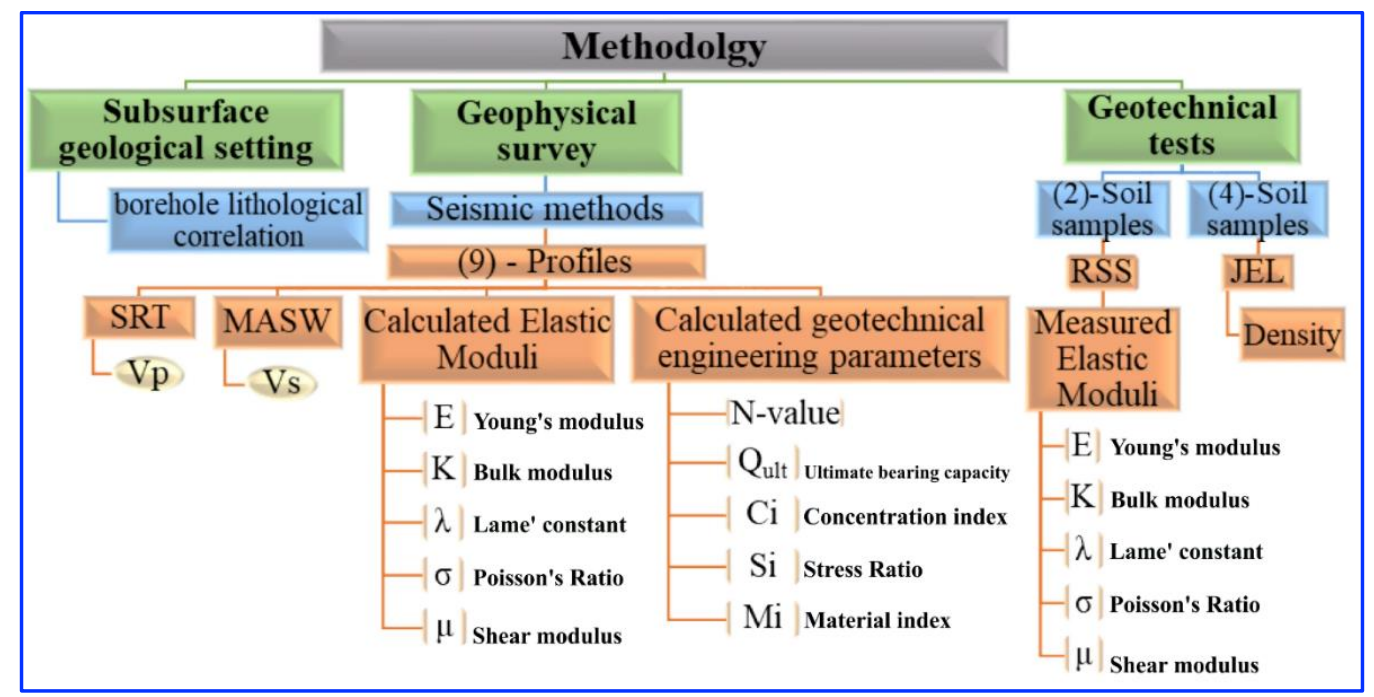

Fig. 2. Flow chart displays the adopted methodology used in this study

\subsection{Geophysical Survey}

\subsubsection{Seismic refraction tomography (SRT)}

The basic principle of the SRT method is depending on the seismic waves travel times measurements that critically refracted at the different velocities layers (Ayolabi et al. 2009). In the SRT method, the acoustic velocities increasing with depth. The primary wave velocity data presented as cross-section plots representing the P-wave path, velocities, and depths to various velocity layers and analyzing the propagation of seismic primary waves created. The objective is to produce a 2-D primary velocity (Vp) section (Anomohanran, 2013). The objective of the SRT method is to determine the subsurface layers using a velocity of primary wave (Vp) as a 2-D cross-section. The 2D sections (Vp and Vs) display different characteristics, depending on the lithology changes or subsurface properties.

\subsubsection{Multichannel analyses shear wave (MASW)}

The basic principle of the MASW method is depending on measuring and analyzing the propagation of seismic Rayleigh surface waves created from different seismic sources. (Park et al. 1999). The key parameter of the accuracy of MASW data analyses is the deducing of an accurate dispersion curve. Dispersion curve is a relation between the frequency and the phase velocity as shown in (Fig. 3d) (Olafsdottir et al. 2018). The main objective of the MASW method is to characterize the shallow subsurface layering and to support estimating the fundamental elastic properties of the topsoil layer for civil infrastructure constructions. Fig. 3 summarizes the main steps of processing of MASW data to deduce the 2-D shear wave velocity (Vs) section.

\subsubsection{Data acquisition and processing}

Nine seismic profiles $60 \mathrm{~m}$ long were conducted in this study. Geometrics Smart Seis instrument was used for data collection. The system consists of twelve geophones of $4.5 \mathrm{~Hz}$ frequency, vertical geophones. The geophone spacing was $3 \mathrm{~m}$ for profiles No. 5 to 9 , and $5 \mathrm{~m}$ for profiles No. 1 to 4 . A $10 \mathrm{~kg}$ sledgehammer on a striker plate was used as the source of energy. The data were recorded with a sample interval of 1 millisecond in a time-window of 1024 milliseconds. The analysis of seismic data was done by Seis Imager/SW ${ }^{\mathrm{TM}}$ software. 


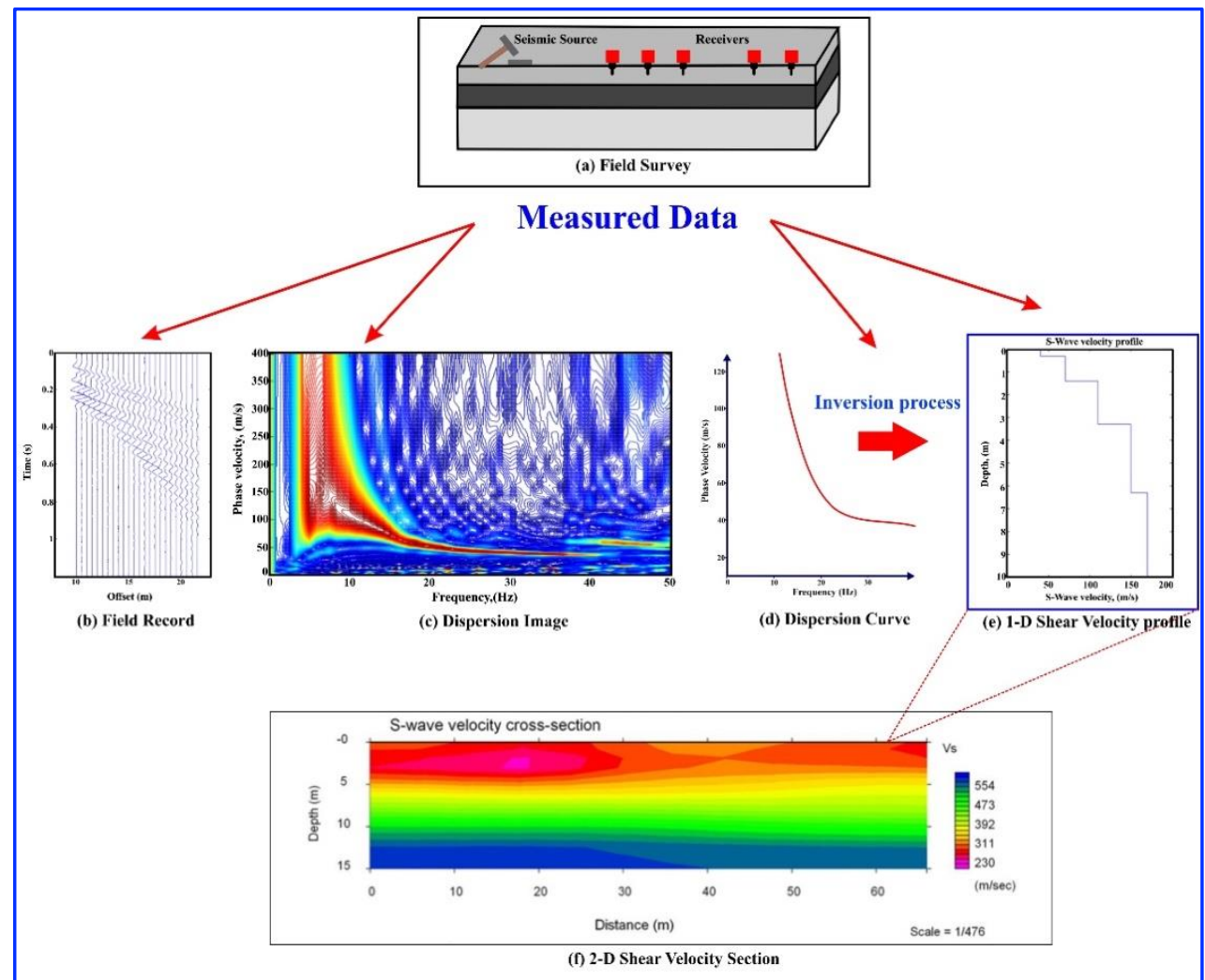

Fig. 3. Summary of main steps of MASW data processing and deducing the 2-D shear velocity (Vs) section (Modified after Olafsdottir et al. 2018)

\subsection{Elastic Moduli and Geotechnical Engineering Parameters}

\subsubsection{Elastic moduli and seismic velocities}

The elastic moduli can be calculated using the seismic velocities (Primary velocity (Vp) and Shear velocity (Vs)) obtained by MASW and SRT methods to give a better engineering understanding of the subsurface layers (Khalil and Hanafy, 2016). These moduli are Young's modulus (E), Shear modulus $(\mu)$, Bulk modulus $(K)$, Lame's constant $(\lambda)$ and Poisson's ratio $(\sigma)$. Young's modulus $(E)$ and shear modulus $(\mu)$ can be determined from defined formulas based on the density $(\rho)$ information (Table 1$)$. The shear wave velocity (Vs) is considered as an important parameter to estimate the elastic moduli, therefore, shear modulus $(\mu)$ can be determined fully presicelyonce shear velocity is known, whereas to calculate the Young's modulus (E) from equations, Poisson's ratio $(\sigma)$ must be known to obtain a comparable accurate value (Patil et al. 2017). Table 1 lists some of the inter-relationships between different elastic moduli and density of the rocks for homogeneous and isotropic media.

Table 1. Elastic moduli and seismic velocities inter-relationships

\begin{tabular}{lcc}
\hline Elastic moduli & Used formula & Reference \\
\hline Young's modulus $(\mathrm{E})$ & $\mathrm{E}=2 \rho \mathrm{V}_{\mathrm{s}}^{2}(1+\sigma)$ & (Park, 2013) \\
Shear modulus $(\mu)$ & $\mu=\rho \mathrm{V}_{\mathrm{s}}^{2}$ & (Birch, 1961) \\
Bulk modulus $(\mathrm{K})$ & $\mathrm{K}=\rho\left(\mathrm{V}_{\mathrm{p}}^{2}-\left(\frac{4}{3}\right) \mathrm{V}_{\mathrm{s}}^{2}\right)$ & (Birch, 1961) \\
& $\sigma=\frac{1}{2}\left[1-\frac{1}{\left(\frac{\mathrm{V}_{\mathrm{p}}}{\mathrm{V}_{\mathrm{s}}}\right)^{2}-1}\right]$ & \\
Poisson's ratio $(\sigma)$ & $\lambda=\rho\left(\mathrm{V}_{\mathrm{p}}^{2}-2 \mathrm{~V}_{\mathrm{s}}^{2}\right)$ & (Christensen, 1996) \\
Lame' constant $(\lambda)$ & & (Birch, 1961) \\
\hline
\end{tabular}




\subsubsection{Geotechnical engineering parameters and seismic velocities}

The geotechnical engineering parameters are estimated depending on the information of soil densities and seismic wave velocities (Vp and Vs) to evaluate the suitability of subsurface construction materials (Abudeif et al. 2019). Table 2 lists the used equations of geotechnical parameters and their inter-relationships.

Table 2. Definitions of geotechnical engineering parameters

\begin{tabular}{lcc}
\hline Geotechnical engineering parameters & Used formula & Reference \\
\hline N-value & $\mathrm{Vs}_{\mathrm{s}}=89.9^{*} N^{0.341}$ & (Stümpel et al., 1984) \\
Ultimate bearing capacity $\left(\mathrm{Q}_{\mathrm{ult}}\right)$ & $\mathrm{Q}_{\mathrm{ult}}=30^{*} N$ & (Parry, 1977) \\
Allowable bearing capacity $\left(\mathrm{Q}_{\mathrm{a}}\right)$ & $\mathrm{Q}_{\mathrm{a}}=\mathrm{Q}_{\mathrm{ult}} / \mathrm{F}^{*}$ & (Parry, 1977) \\
Concentration index $\left(\mathrm{C}_{\mathrm{i}}\right)$ & $\mathrm{C}_{\mathrm{i}}=(1+\sigma) / \sigma$ & (Bowels, 1982) \\
Stress ratio $\left(\mathrm{S}_{\mathrm{i}}\right)$ & $\mathrm{S}_{\mathrm{i}}=\sigma /(1-\sigma)$ & (Thomsen, 1986) \\
Material index $\left(\mathrm{M}_{\mathrm{i}}\right)$ & $\mathrm{M}_{\mathrm{i}}=(1-4 \sigma)$ & (Abd El-Rahman, 1989). \\
(*) F: factor of safety equal 2 for the cohesionless & & \\
\hline
\end{tabular}

\subsubsection{Elastic moduli and geotechnical tests}

Table 3 lists some of the inter-relationships between Young's modulus (E) and Bulk modulus (K) of homogeneous isotropic linear elastic materials to calculate Shear modulus $(\mu)$, Poisson's ratio $(\sigma)$ and Lame' constant $(\lambda)$ (Birch, 1961), that are used in this study.

Table 3. Formulas used to calculate the elastic moduli from Young's modulus (E) and Bulk modulus (K) (After Birch, 1961)

\begin{tabular}{lccc}
\hline Elastic moduli & Used formula & Elastic moduli & Used formula \\
\hline Young's modulus $(\mathrm{E})$ & $\mathrm{E}=2 \mu(1+\sigma)$ & Bulk modulus $(\mathrm{K})$ & $\mathrm{K}=\frac{\mathrm{E}}{3(1-2 \sigma)}$ \\
Shear modulus $(\mu)$ & $\mu=\frac{3 \mathrm{~K} . \mathrm{E}}{9 \mathrm{~K}-\mathrm{E}}$ & Poisson's Ratio $(\sigma)$ & $\sigma=\frac{3 \mathrm{~K}-\mathrm{E}}{6 \mathrm{~K}}$ \\
\hline
\end{tabular}

\section{Results and Discussion}

\subsection{Boreholes Lithological Correlation}

A lithological correlation between the four boreholes logs located inside the university campus (Fig. 4): Faculty of Engineering (E), Faculty of Nursing (N), Olympic swimming pool (P) and Student activities complex (A), has been made and presented in Fig. 5. It was found that the topsoil can be described as clayey silty sand at $2 \mathrm{~m}$ depth, the soil mixed with gravel of limestone and chert and at the $5 \mathrm{~m}$ below surface the soil mixed with chalky marl and gravel of chert and limestone (AABU, 2018). Generally, the compaction degree of soil increases with depth.

\subsection{Seismic Interpretation}

Nine seismic profiles (MASW and SRT survey) have been conducted in this study. Fig. 4 shows the location of seismic measurements. Table (4) summarizes the layering parameters of seismic measurements: number of layers, their primary velocities (Vp), shear velocities (Vs), thicknesses and profiles orientation. Fig. 6 shows the SRT and MASW sections of seismic profile-1 and seismic profile2. Fig. 6a shows a good correlation between the lithological units (EN-Log) and the P-velocity section. Two subsurface layers were identified by the MASW section (Fig. 6b). Fig. 6c shows SRT section of Pvelocity distribution for seismic profile-2. It shows a good correlation between the lithological units (IT-Log) information and seismic section. The SRT and MASW sections show three subsurface layers 
(Figs. 6c and 6d respectively). Figs 7a and 7b show the SRT and MASW sections respectively for seismic profile-3. The results were correlated with P-Log. The results show a good correlation between the subsurface geological layers and primary velocity distribution (Fig.7a). MASW section shows almost one layer with slight shear velocity range (290-300) m/s (Fig. 7b). Figs. 7c and 7d shows the SRT and MASW sections for seismic profile-4. SRT shows three subsurface layers (Figure7c), whereas, the MASW section shows almost one subsurface layer with shear velocity in the range (350-450) $\mathrm{m} / \mathrm{s}$ (Fig. 7d).

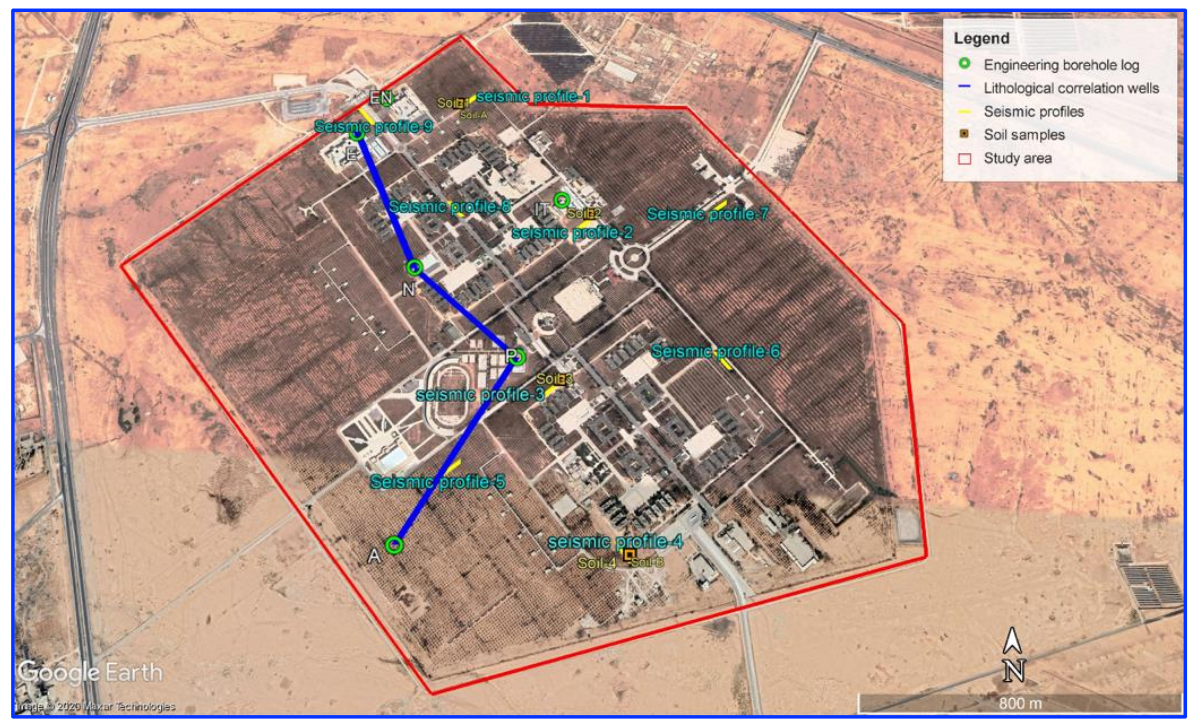

Fig. 4. Location of seismic measurements (MASW and SRT), soil sampling sites and the boreholes lithological correlation in the study area

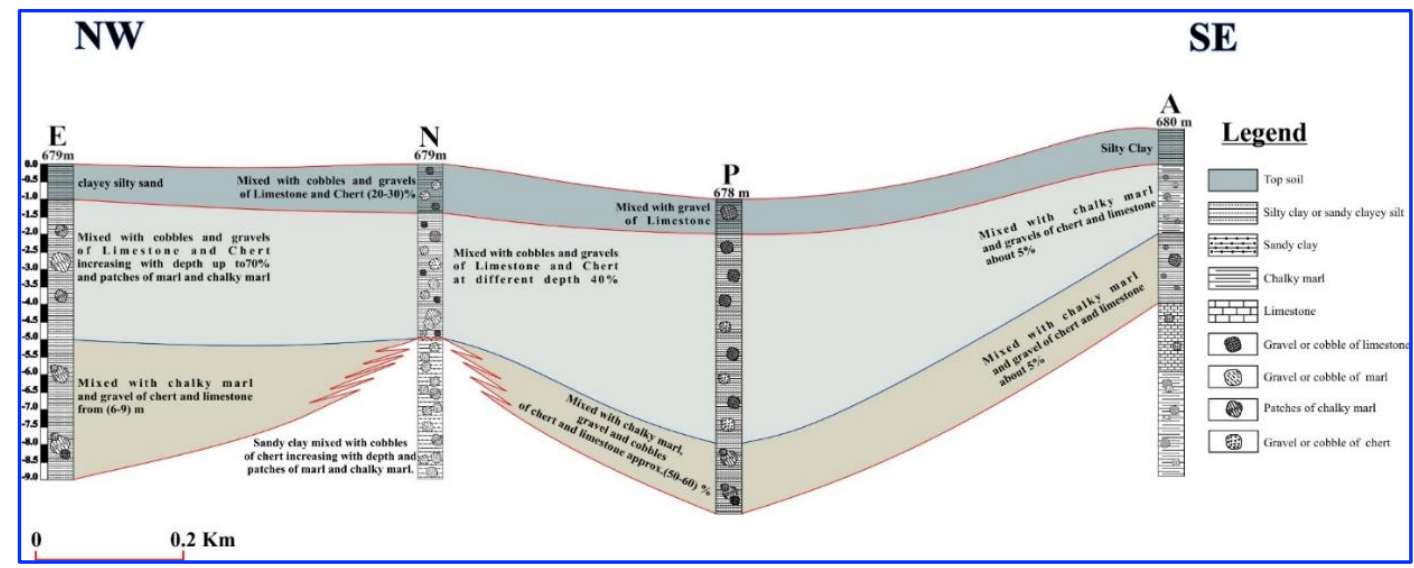

Fig. 5. Detailed lithological description of shallow top soil as correlated between the borehole logs that have been drilled for engineering constructions inside the university (AABU Archive, 2018)

Figs. 8a and 8b show the SRT and MASW sections of seismic profile-5 respectively. The results were correlated with A-Log and displayed a good correlation with the lithological unit and velocity distributions. SRT and MASW sections have large lateral variations of seismic velocity (Figs. 8a and $8 \mathrm{~b}$ respectively) this properly due to lithological variations and/ or due to a possible structural fault. Figs. 8c and 8d show SRT and MASW for seismic profile-6, respectively. The results show three velocity layers. SRT section shows lateral variations of primary seismic velocity $(\mathrm{Vp})$ in the range values (400-1800) $\mathrm{m} / \mathrm{sec}$ (Fig. 8c). Figs. 9a and 9b show SRT and MASW section of seismic profile-7 respectively. The results show three seismic layers. SRT section has primary velocity in the range (255$1400) \mathrm{m} / \mathrm{s}$ (Figure 9 a), while MASW section has a narrow range of shear velocity (200-600) $\mathrm{m} / \mathrm{s}$ (Figure 9b). 
Table 4. The results of nine seismic measurement taken in the study area

\begin{tabular}{|c|c|c|c|c|c|c|}
\hline Seismic Profile & Layers & SRT (Vp) & Thickness & MASW (Vs) & Thickness & Orientation \\
\hline Units & & $\mathrm{m} / \mathrm{s}$ & $\mathrm{M}$ & $\mathrm{m} / \mathrm{s}$ & $\mathrm{m}$ & \multirow{4}{*}{ NE-SW } \\
\hline \multirow{3}{*}{ Seismic Profile-1 } & Layer One & $180-360$ & 1 & 390 & 2 & \\
\hline & Layer Two & $360-700$ & 3 & 340 & 6 & \\
\hline & Layer Three & $743-750$ & 6 & 390 & 2 & \\
\hline \multirow{3}{*}{ Seismic Profile-2 } & Layer One & $150-260$ & 0.5 & $250-260$ & 4 & \multirow{3}{*}{ NE-SW } \\
\hline & Layer Two & $330-370$ & 1.5 & $260-280$ & 4 & \\
\hline & Layer Three & $500-600$ & 7.5 & $300-320$ & 2 & \\
\hline \multirow{3}{*}{ Seismic Profile-3 } & Layer One & $305-350$ & 1 & $300-330$ & 2 & \multirow{3}{*}{ SW-NE } \\
\hline & Layer Two & $490-600$ & 6 & $300-350$ & 4 & \\
\hline & Layer Three & $620-640$ & 3 & $300-380$ & 4 & \\
\hline \multirow{3}{*}{ Seismic Profile-4 } & Layer One & $340-425$ & 1.5 & \multirow{3}{*}{\multicolumn{2}{|c|}{$\begin{array}{l}\text { Whole } \\
\text { section }\end{array}$}} & \multirow{3}{*}{ NW-SE } \\
\hline & Layer Two & $600-740$ & 2.5 & & & \\
\hline & Layer Three & $760-860$ & 6 & & & \\
\hline \multirow{3}{*}{ Seismic Profile-5 } & Layer One & $500-670$ & 4 & $280-300$ & $5-0$ & \multirow{3}{*}{ NE-SW } \\
\hline & Layer Two & $700-870$ & $9-3$ & $340-400$ & $10-7$ & \\
\hline & Layer Three & $900-1000$ & $2-8$ & $410-440$ & $0-8$ & \\
\hline \multirow{3}{*}{ Seismic Profile-6 } & Layer One & $400-650$ & $10.5-7.5$ & $230-300$ & 5 & \multirow{3}{*}{ NW-SE } \\
\hline & Layer Two & $700-900$ & $2-7$ & $330-530$ & 6 & \\
\hline & Layer Three & $1000-1800$ & $2.5-0.5$ & $550-610$ & 4 & \\
\hline \multirow{3}{*}{ Seismic Profile-7 } & Layer One & $250-560$ & 5 & $200-360$ & 4 & \multirow{3}{*}{ SW-NE } \\
\hline & Layer Two & $630-1000$ & 5 & $400-580$ & $11-7$ & \\
\hline & Layer Three & $1300-1500$ & 5 & $600-630$ & $0-4$ & \\
\hline \multirow{3}{*}{ Seismic Profile- 8} & Layer One & $700-850$ & $9-7$ & 520 & $0-4$ & \multirow{3}{*}{ SE-NW } \\
\hline & Layer Two & $920-1200$ & $2.5-3$ & $320-390$ & $15-0$ & \\
\hline & Layer Three & $1400-1800$ & $3.5-5$ & $450-500$ & $0-11$ & \\
\hline \multirow{3}{*}{ Seismic Profile-9 } & Layer One & $440-580$ & $4-0$ & $200-310$ & 4 & \multirow{3}{*}{ NW-SE } \\
\hline & Layer Two & $610-780$ & $3.5-1.5$ & 400520 & 11 & \\
\hline & Layer Three & $800-900$ & $7.5-13.5$ & $400-5<0$ & 11 & \\
\hline
\end{tabular}

Figs. 10a and10b show the SRT and MASW section of seismic profile- 8 respectively. The results show three seismic layers. Primary velocity (Vp) is ranging from $700 \mathrm{~m} / \mathrm{sec}$ to $1800 \mathrm{~m} / \mathrm{sec}$ (Fig. 10a). MASW section has large lateral variations of shear seismic velocity this properly due to lithological variations and/ or due to a possible structural fault (Fig. 10b).

Figs. 10c and 10d show SRT and MASW sections for seismic profile-9. SRT section has a lateral variation of primary velocity in the range (440-900) $\mathrm{m} / \mathrm{sec}$ (Fig. 10c). Whereas MASW section shows two seismic layers with velocity ranges between 200 and $520 \mathrm{~m} / \mathrm{sec}$ (Fig. 10d).

\subsubsection{Geotechnical results deduced from seismic and lab testing}

In this study, the seismic methods were used for shallow subsurface characterization and to estimate the different elastic properties of superficial deposits. Based on the modeling results of seismic velocities ( $\mathrm{Vp}$ and $\mathrm{Vs}$ ) and using appropriate equations (Table 1), the elastic moduli for the shallow subsurface soil layer were calculated. The results are listed in Table 5. 


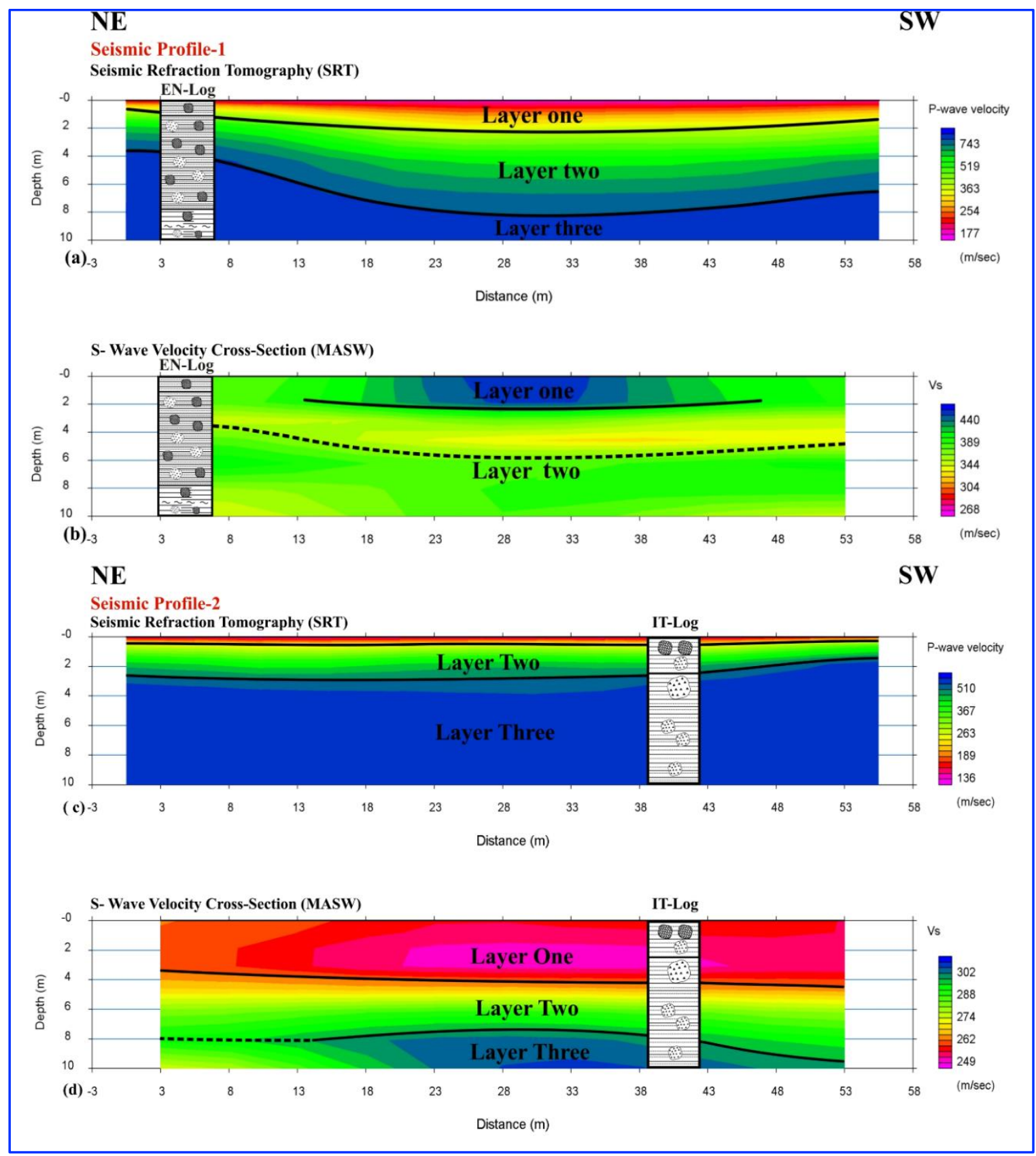

Fig. 6. (a) 2-D Primary wave velocity section for seismic profile-1; (b) 2-D Shear wave velocity section for seismic profile-1; (c) 2-D Primary wave velocity section for seismic profile-2; (d) 2-D Shear wave velocity section for seismic profile-2 


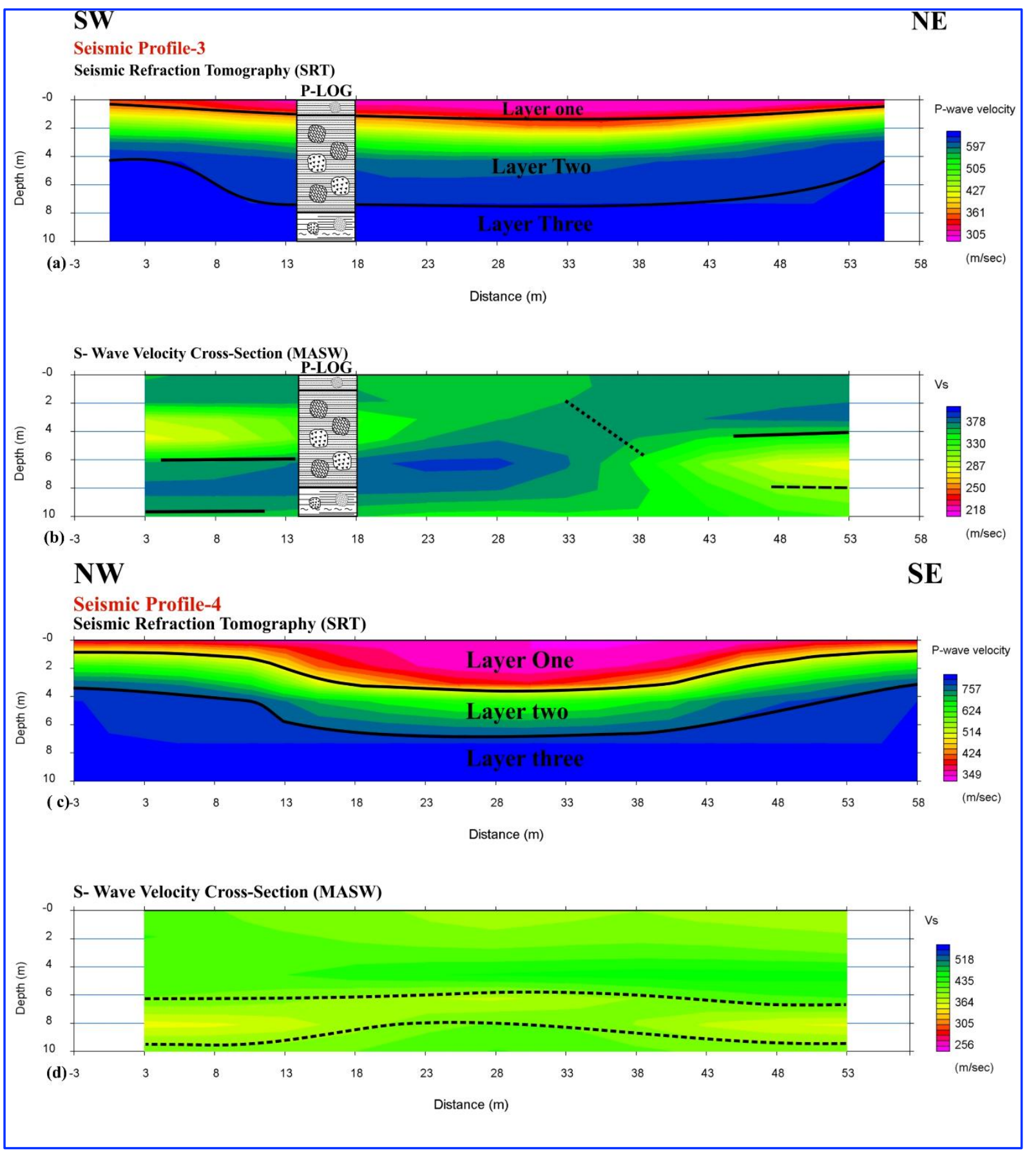

Fig. 7. (a) 2-D Primary wave velocity section for seismic profile-3; (b) 2-D Shear wave velocity section for seismic profile-3; (c) 2-D Primary wave velocity section for seismic profile-4; (d) 2-D Shear wave velocity section for seismic profile-4 


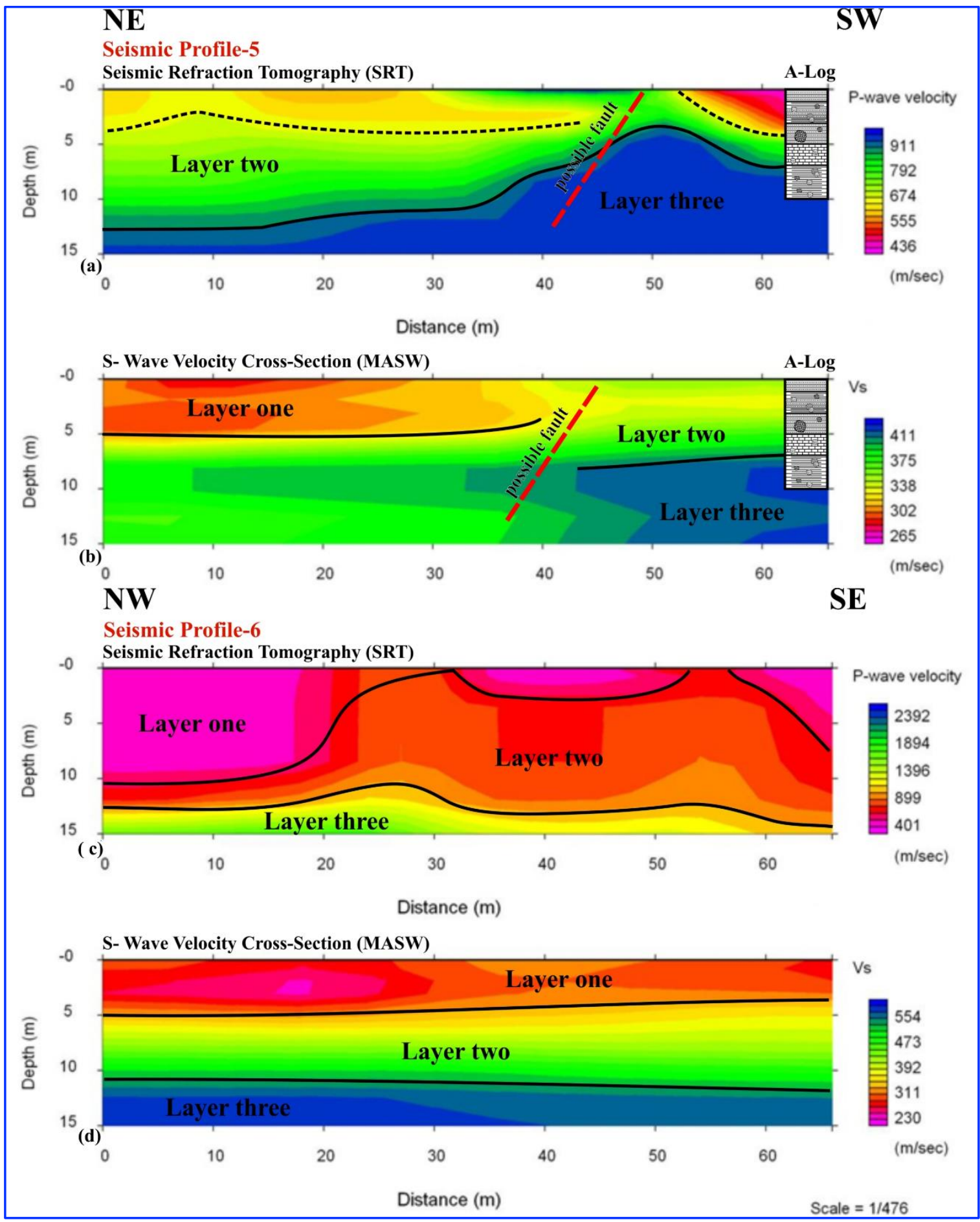

Fig. 8. (a) 2-D Primary wave velocity section for seismic profile-5; (b) 2-D Shear wave velocity section for seismic profile-5; (c) 2-D Primary wave velocity section for seismic profile-6; (d) 2-D Shear wave velocity section for seismic profile-6 


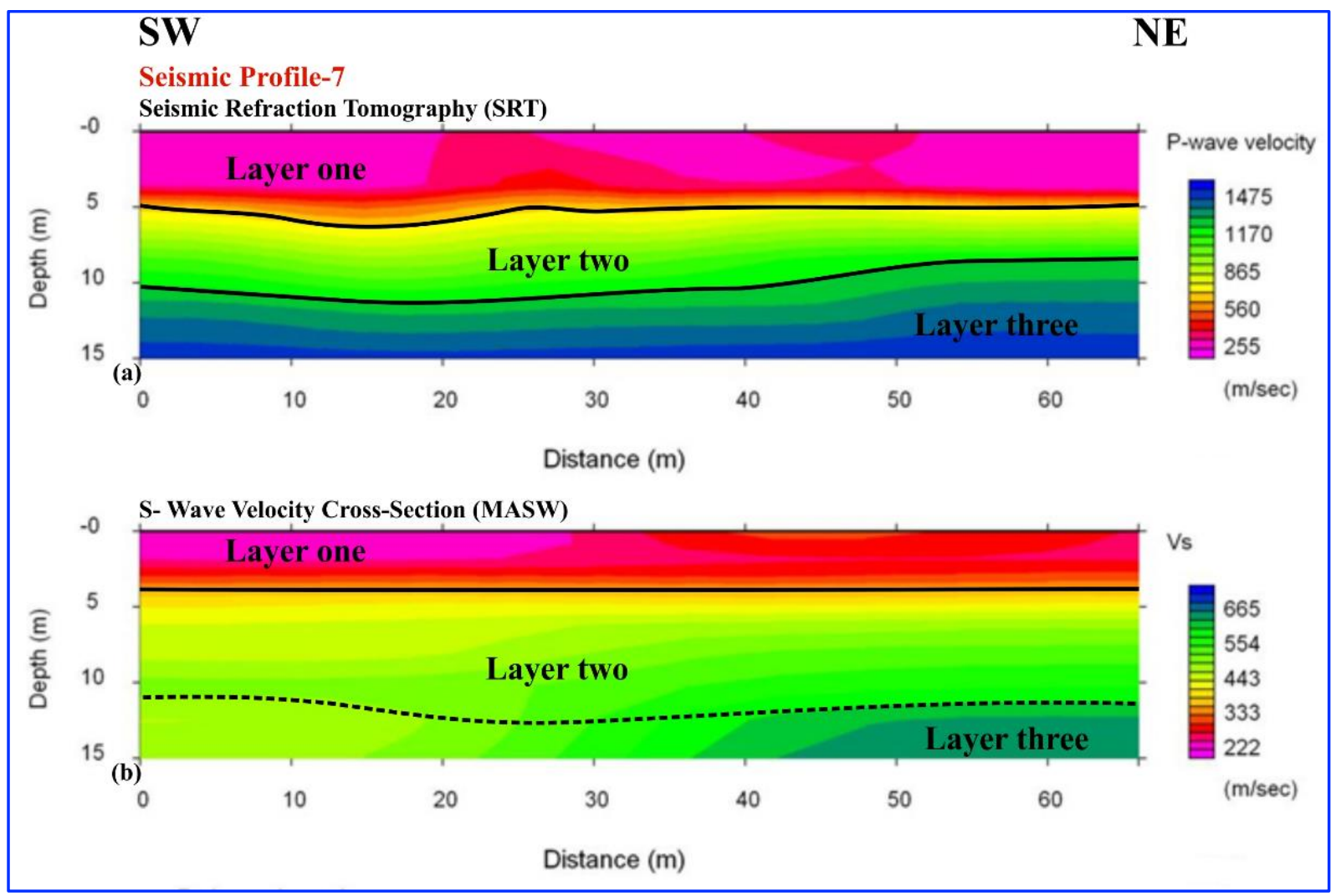

Fig. 9. (a) 2-D Primary wave velocity section for seismic profile-5; (b) 2-D Shear wave velocity section for seismic profile-5

Moreover, the elastic moduli (K and E) were measured at Royal Scientific Society (RSS) for samples A and B and the results are presented in Table 6. They are also used to calculate the following elastic constants (Poisson's ratio $(\sigma)$, Lame' Constant $(\lambda)$ and Shear modulus $(\mu)$ ) using the relationships listed in Table (3). For results verification, a comparison has been made between the elastic constants computed from seismic velocities (Samples 1 and 4) and those computed from $\mathrm{K}$ and $\mathrm{E}$ measured in RSS lab tests (Samples A and B). Fig. 11 shows a comparison between the geotechnical properties calculated from seismic velocities of MASW measurements with those measured in RSS laboratories. It was found that the Poisson's ratios $(\sigma)$ measured at RSS laboratories are higher than those calculated by MASW measurements, but both of them indicate to soft, loose unconsolidated soil material types shown as Fig. 11c. On the contrary, the shear modulus $(\mu)$, Bulk modulus $(\mathrm{K})$ and Lame's Constant $(\lambda)$ calculated from seismic velocities MASW measurements were found to be higher than those measured in RSS laboratories shown as Figs.11b, 11d and 11e respectively. Fig.11a shows a Young's modulus (E) calculated from MASW measurements were highly correlated with those measured in RSS laboratories. The small changes between the measured and calculated elastic properties can be ascribed to different reasons such as, the used formulas to calculate the geotechnical properties assumed isotropic, homogeneous subsurface which is not the case. 


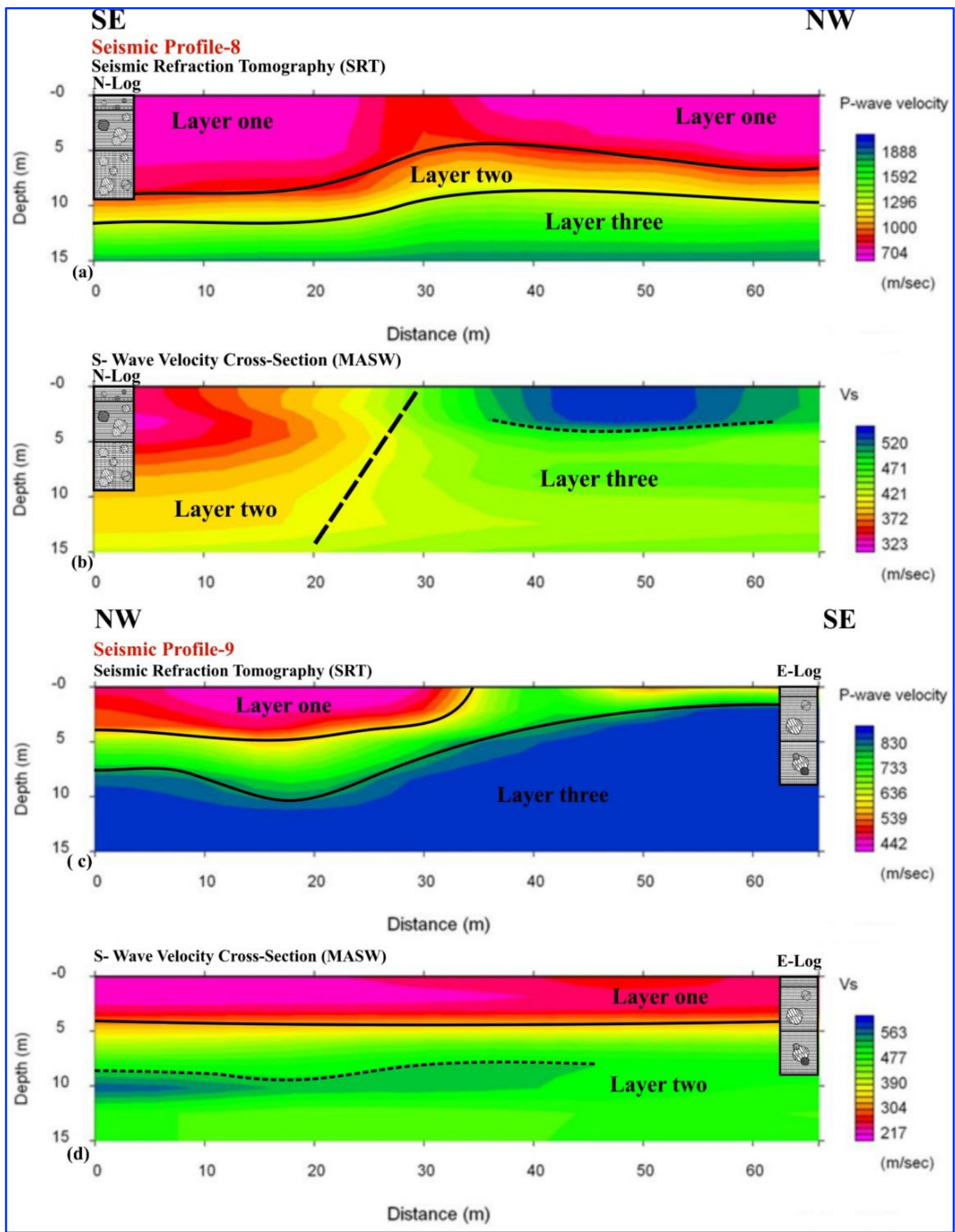

Fig. 10. (a) 2-D Primary wave velocity section for seismic profile-8; (b) 2-D Shear wave velocity section for seismic profile-8; (c) 2-D Primary wave velocity section for seismic profile-9; (d) 2-D Shear wave velocity section for seismic profile-9 
Table 5. Elastic moduli as calculated from seismic velocities (SRT and MASW) measurements for the depth $2 \mathrm{~m}$ to $3 \mathrm{~m}$

\begin{tabular}{|c|c|c|c|c|c|c|c|c|}
\hline $\begin{array}{l}\text { Seismic Profile } \\
\text { Numbers }\end{array}$ & $\begin{array}{l}\text { SRT } \\
(\mathbf{V p})\end{array}$ & $\begin{array}{c}\text { MASW } \\
(\mathbf{V s})\end{array}$ & Density & $\begin{array}{c}\text { Poisson's } \\
\text { Ratio }\end{array}$ & $\begin{array}{l}\text { Shear } \\
\text { Modulus }\end{array}$ & $\begin{array}{l}\text { Young's } \\
\text { Modulus }\end{array}$ & $\begin{array}{c}\text { Bulk } \\
\text { Modulus }\end{array}$ & $\begin{array}{c}\text { Lame' } \\
\text { Constant }\end{array}$ \\
\hline Symbol's & & & $\rho$ & $\Sigma$ & $\mathbf{M}$ & $\mathbf{E}$ & $\mathbf{K}$ & $\lambda$ \\
\hline Units & $\mathbf{m} / \mathbf{s}$ & $\mathbf{m} / \mathbf{s}$ & $\mathrm{g} / \mathrm{cm}^{3}$ & & GPa & GPa & GPa & GPa \\
\hline Profile-1 (Sample-A) & 690 & 355 & $1.89^{*}$ & 0.32 & 0.00024 & 0.00063 & 0.58 & 0.42 \\
\hline Profile -2 & 510 & 250 & $1.86^{*}$ & 0.34 & 0.00012 & 0.00031 & 0.33 & 0.25 \\
\hline Profile -3 & 600 & 310 & $1.82^{*}$ & 0.32 & 0.00018 & 0.00046 & 0.42 & 0.31 \\
\hline $\begin{array}{l}\text { Profile -4 } \\
\text { (Sample-B) }\end{array}$ & 720 & 420 & $1.82^{*}$ & 0.24 & 0.00032 & 0.00080 & 0.52 & 0.30 \\
\hline Profile -5 & 600 & 320 & $1.82^{* *}$ & 0.30 & 0.00019 & 0.00049 & 0.41 & 0.28 \\
\hline Profile -6 & 650 & 290 & $1.82^{* *}$ & 0.38 & 0.00015 & 0.00042 & 0.56 & 0.46 \\
\hline Profile -7 & 480 & 280 & $1.82^{* *}$ & 0.24 & 0.00014 & 0.00035 & 0.23 & 0.13 \\
\hline Profile -8 & 800 & 440 & $1.82^{* *}$ & 0.28 & 0.00035 & 0.00090 & 0.69 & 0.46 \\
\hline Profile -9 & 650 & 300 & $1.82^{* * *}$ & 0.36 & 0.00016 & 0.00045 & 0.55 & 0.44 \\
\hline
\end{tabular}

(*) Density measured at Jordan Engineering Laboratories (JEL) laboratory tests. (**) Assumed Density.

Table 6. Elastic moduli measured in laboratory test at RSS

\begin{tabular}{cccccc}
\hline $\begin{array}{c}\text { Seismic Profiles } \\
\text { Numbers }\end{array}$ & $\begin{array}{c}\text { Young's } \\
\text { Modulus* }\end{array}$ & $\begin{array}{c}\text { Bulk } \\
\text { Modulus* }\end{array}$ & Poisson's Ratio & $\begin{array}{c}\text { Shear } \\
\text { Modulus }\end{array}$ & $\begin{array}{c}\text { Lame' } \\
\text { Constant }\end{array}$ \\
\hline Symbol's & $\mathrm{E}$ & $\mathrm{K}$ & $\Sigma$ & $\mu$ & $\lambda$ \\
Units & $\mathrm{GPa}$ & $\mathrm{GPa}$ & Dimensionless & $\mathrm{GPa}$ & $\mathrm{GPa}$ \\
Sample-A (profile-1) & 0.00061 & 0.196 & 0.4995 & 0.000203 & 0.195 \\
Sample-B (profile -4) & 0.00065 & 0.29 & 0.4996 & 0.000216 & 0.289 \\
\hline
\end{tabular}

(*) Young's and bulk moduli deduced from RSS laboratory tests.

\subsection{Elastic Moduli and Geotechnical Engineering Parameters}

A spatial contouring map for the different geotechnical parameter has been made and the results are presented in Figs. 12, 13, and 14. Fig. 12a shows a spatial contour map for Shear Modulus $(\mu)$. It is varying from $0.0016 \mathrm{Gpa}$ at NE and SW parts to $0.00037 \mathrm{Gpa}$ in the NW and SE parts of the study area. The Bulk Modulus (K) is ranging between 0.25 and 0.75 Gpa (Figure 12b).

Fig. 12c shows a Poisson's ratio $(\sigma)$ contouring map. It shows that the Poisson's ratio is varying from 0.22 in the northeastern and southern parts of the study area to 0.34 in the south eastern and northwestern parts of the study area. Fig. 12d shows a spatial contouring map for Young's modulus (E). It shows that Young's modulus ranges from 0.001 to $0.0009 \mathrm{Gpa}$. The young's modulus values increase in NW and SE parts of the study area and decreases in NE and SW parts. The study area can be classified into three zones according the K values, they area, the highest values located in the NW part, the lowest values located in the NE part and the intermediate values zone located in the southern part of the study area. Lame' Constant $(\lambda)$ ranges from $0.07 \mathrm{Gpa}$ to $0.49 \mathrm{Gpa}$. The lowest value is located in the northeastern part and the highest value is located in the northwestern part of the study area (Fig.13a). The calculated allowable bearing capacity $(\mathrm{Q})_{\mathrm{a}}$ values range from $0.5 \mathrm{~kg} / \mathrm{cm}^{2}$ to $2 \mathrm{~kg} / \mathrm{cm}^{2}$ (Fig.13b). The calculated Ultimate bearing capacity (Qult) values range from $1 \mathrm{~kg} / \mathrm{cm}^{2}$ to $4 \mathrm{~kg} / \mathrm{cm}^{2}$ (Fig. 13c). The highest values of bearing capacity are shown in the NW part of the study area. Fig.13d shows a spatial contouring map for $\mathrm{N}$-value. It shows that the $\mathrm{N}$-value is ranging from 40 at $\mathrm{NE}$ and $\mathrm{SW}$ part to 160 in the NW part of the study area. 


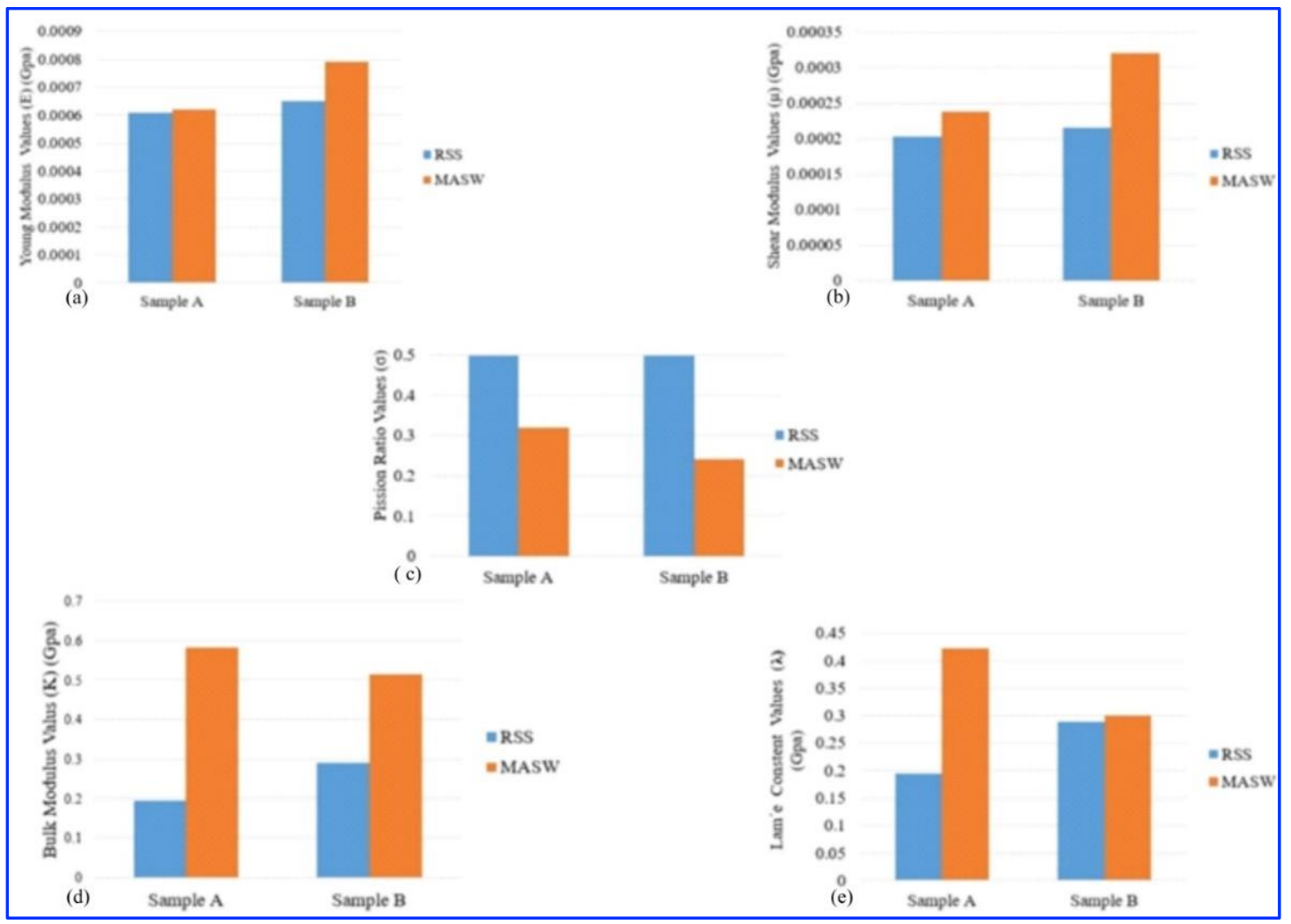

Fig.11. Comparison between calculated and measured elastic moduli

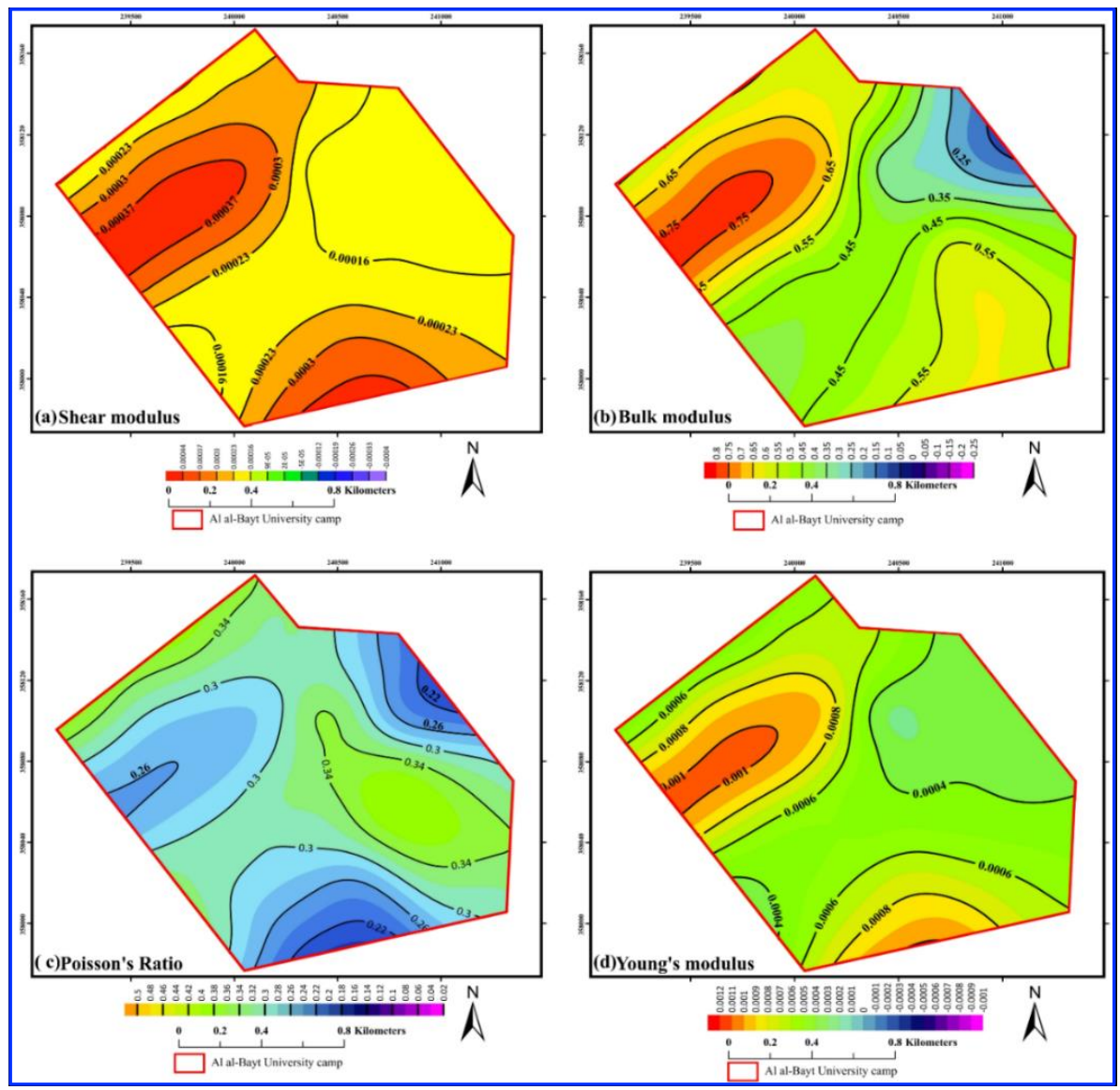

Fig. 12. Spatial contour maps of the elastic moduli and geotechnical engineering parameters for the depth $2 \mathrm{~m}$ to $3 \mathrm{~m}$ of subsurface layers. (a) Shear modulus; (b) Bulk modulus ;(c) Poisson's ratio; (d) Young's modulus 

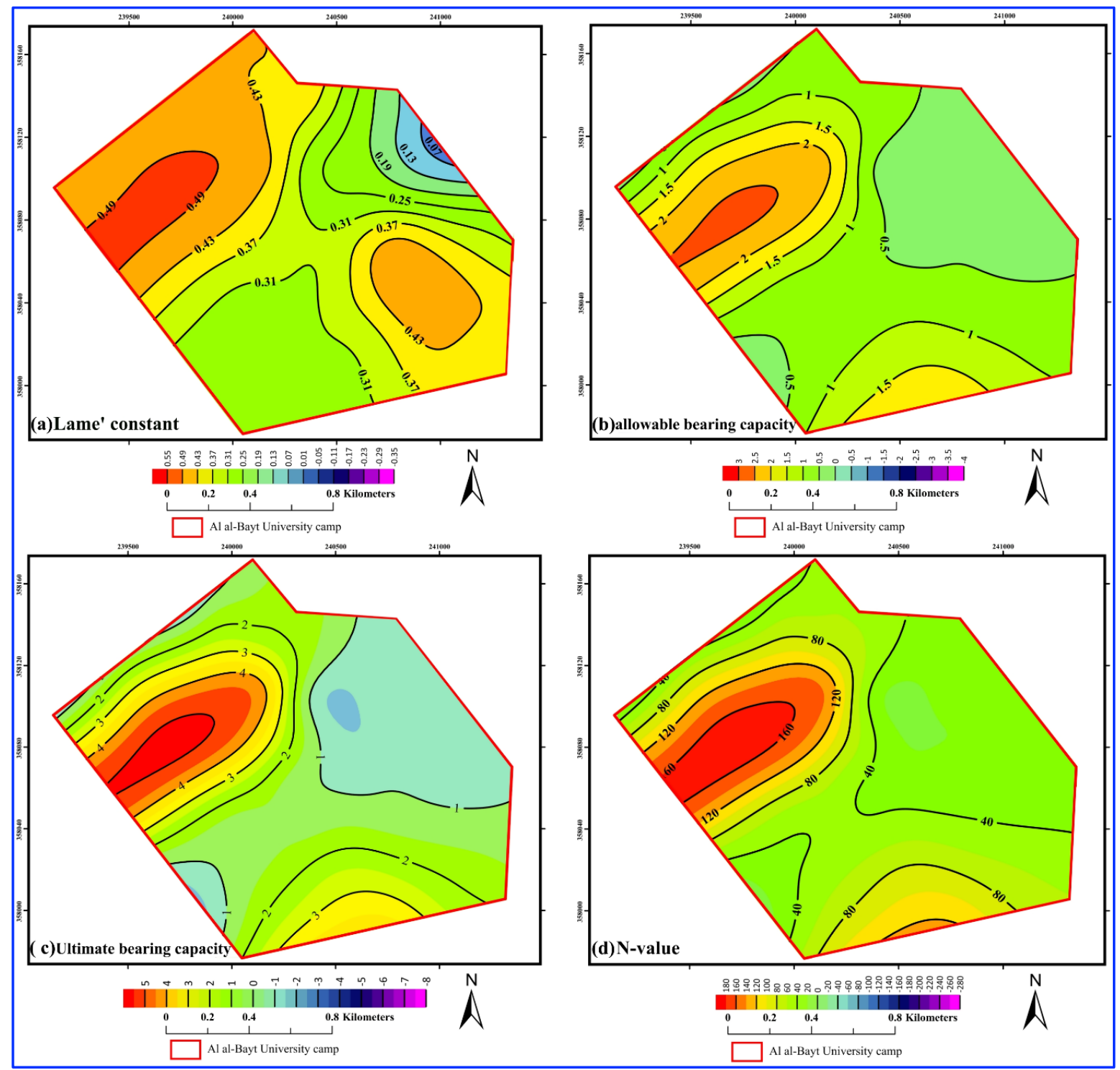

Fig. 13. Spatial contour maps of the elastic moduli and geotechnical engineering parameters for the depth $2 \mathrm{~m}$ to $3 \mathrm{~m}$ of subsurface layers. (a) Lame' Constant; (b) allowable bearing capacity; (c) Ultimate bearing capacity; (d)

$\mathrm{N}$-value

Fig. 14a shows stress ratios ( $\mathrm{Si}$ ) contouring map. The stress ratio ranges from 0.25 to 0.61 . The smallest stress ration $(\mathrm{Si})$ values were found at the northwestern parts of the study area, while the largest values were found at the southeastern part of the study area indicating that, this area includes less competent materials than the rest parts of the study area. Fig. 14c shows the concentration index (Ci) contouring map. It ranges from 4.5 to 6.5. The highest value was found in the NW part of the study area. Fig. 14d shows the spatial contouring map of material index (Mi). It shows that the material index (Mi) is varying from -0.4 at NE and S parts to 0.2 in the SE and NW parts of the study area. The higher the material index values are indicating to higher competent materials. 


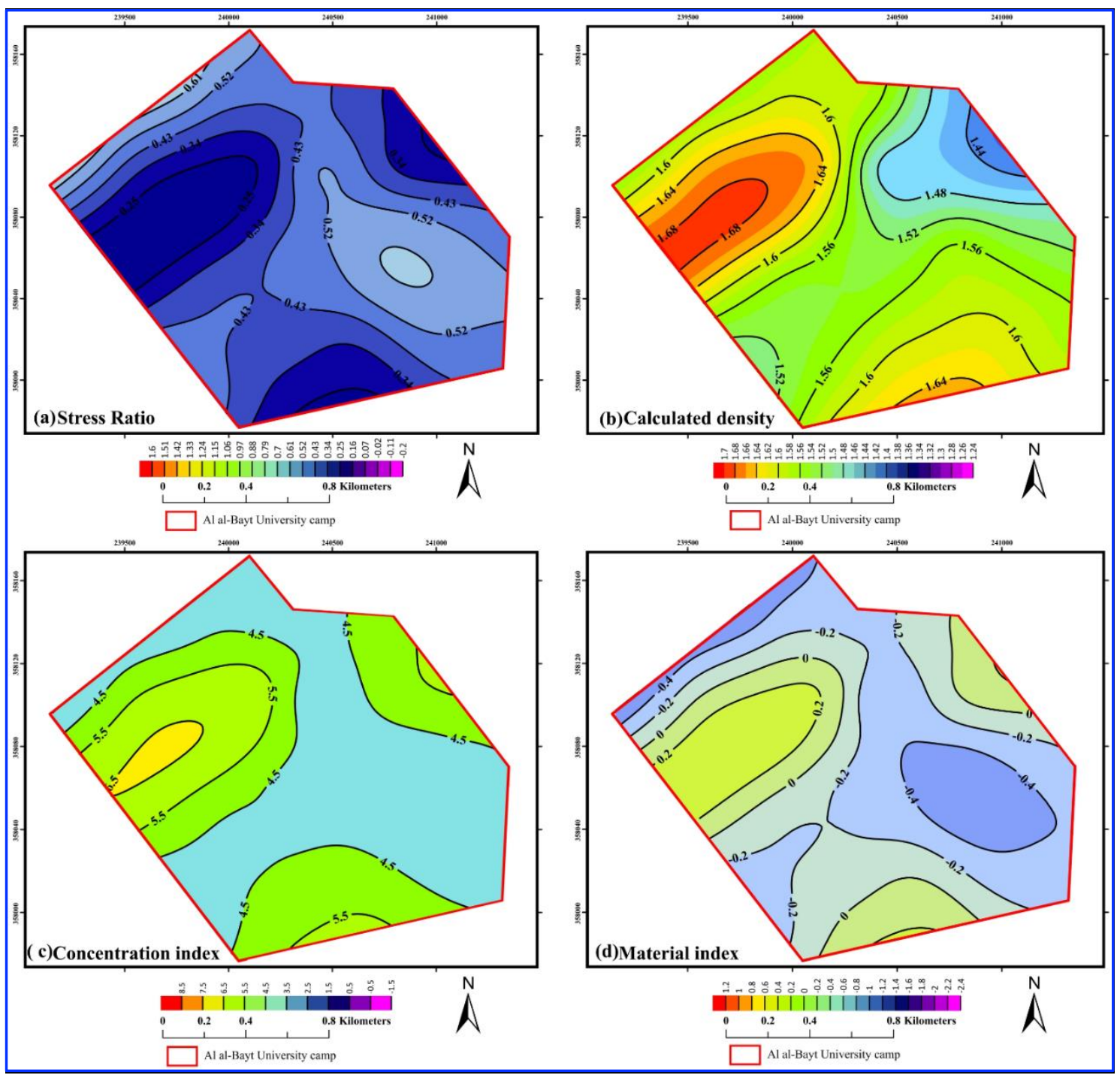

Fig. 14. Spatial contour maps of the elastic moduli and geotechnical engineering parameters for the depth $2 \mathrm{~m}$ to $3 \mathrm{~m}$ of subsurface layers. (a) Stress ratio; (b) Calculated density (c) Concentration index; (d) Material index

\section{Conclusions}

The seismic results permitted the characterization of subsurface geology for a depth of only $10 \mathrm{~m}$ below ground surface. The SRT method helped in defining three subsurface zones based on the inversion of seismic P-wave velocity. The P-wave refraction velocities were found to range from 180 to $2300 \mathrm{~m} / \mathrm{s}$ for the three identified layers indicating superficial soil deposits with increasing degree of compaction with depth. The S-wave velocities were found to lie in a slight velocity range from 250 to $600 \mathrm{~m} / \mathrm{s}$ that poorly resolved the subsurface layering. The seismic velocities deduced from SRT and MASW measurements were used to estimate the elastic moduli and geotechnical properties of the shallow superficial deposits. As comparing the geotechnical properties calculated from seismic velocities with those measured in RSS laboratories, it was found that the Poisson's ratio $(\sigma)$ measured at RSS laboratories are higher than those calculated from seismic measurements, but both of them indicate a soft, loose unconsolidated soil material types. On the contrary, the shear modulus $(\mu)$, Bulk modulus (K) and Lame' Constant $(\lambda)$ calculated from seismic velocities measurements were found to be higher than those measured in RSS laboratories. In addition, the collected soil samples for geotechnical testing were in a friable, disturbed and non-cohesive state. 
The integration among seismic techniques (MASW and SRT) was proved to be an efficient means to describe near the surface and superficial soil deposits. In other words, these techniques were useful to identify the soil layer and detect the soil compaction degree. In addition, the seismic methods were also effective tools to estimate the different dynamic elastic properties of the soil layer that can be used for future engineering construction.

\section{Acknowledgements}

We gratefully acknowledge the $\mathrm{Al}$ al-Bayt University and Hashemite University, for providing the seismic instrumentation. The authors appreciate very much Mr. Jafar Abu Rajab and Mr. Adnan Rezq for assistance in the seismic field surveys. The authors are very grateful to the Editor in Chief Prof. Dr. Salih M. Awadh, the Secretary of Journal Mr. Samir R. Hijab. and the Technical Editors for their great efforts and valuable comments.

\section{References}

Abd El-Rahman, M., 1989. Evaluation of the kinetic elastic modulii of the surface materials and application to engineering geologic maps at Maba-Risabah area (Dhamar Province), Northern Yemen, Egypt. Journal Geology, 33(1-2): 229-250.

Abudeif, A. M., Fat-Helbary, R. E., Mohammed, M. A., Alkhashab, H. M., Masoud, M. M., 2019. Geotechnical engineering evaluation of soil utilizing 2D multichannel analysis of surface waves (MASW) technique in New Akhmim city, Sohag, Upper Egypt. Journal of African Earth Sciences, 157:1-10.

Al-Ansari, N. A., Baban, S. J., 2001. The climate and water resources. Living With Water Scarcity, Water Resources in the Jordan Badia Region, The Way Forward.

Al-Heety, A. R., Shanshal, Z. M., 2016. Integration of seismic refraction tomography and electrical resistivity tomography in engineering geophysics for soil characterization. Arabian Journal of Geosciences, 9(1): 73.

Al-Kubaisi, M. S., Shakir, M.M., 2018. Structural analysis for the plunge areas of bekhair, brifca, dohuk and zawita anticlines northern iraq using seismic sections. Iraqi Geological Journal, 51(1): 56-68.

Al-Saigh, N. H., Al-Heety, A. J., 2013. Seismic refraction tomography and MASW survey for geotechnical evaluation of soil for the teaching hospital project at Mosul University. Journal of Zankoy Sulaimani, Part A, 16(1): 1-14.

Alsamarraie, M. M., 2020. Seismic refraction method in the determination of site characteristics. Iraqi Geological Journal, 53(2D):53-63.

Al Al-Bayt University (AABU) archive., 2018. Engineering boreholes logs reports. Construction and material laboratories. Unpublished reports.Done by Royal Scientific Society (RSS).

Anomohanran, O., 2013. Seismic refraction method: A technique for determining the thickness of stratified substratum. American Journal of Applied Sciences, 10(8), 857-862.

Ayolabi, E. A., Adeoti, L., Oshinlaja, N. A., Adeosun, I. O., Idowu, O. I., 2009. Seismic refraction and resistivity studies of part of Igbogbo township, south-west Nigeria, 11: 42-61.

Benson, C., Yuhr, L., 2002. Site characterization strategies: old and new. Second Annual Conference on the Application of Geophysical and NDT Methodologies to Transportation Facilities, Federal Highway AdMinistration, 15-19.

Benson, R. C., Glaccum, R. A., Noel, M. R., 1983. Geophysical techniques for sensing buried wastes and waste migration. Environmental Monitoring Systems Laboratory, Office of Research and Development, US Environmental Protection Agency.

Birch, F., 1961. The velocity of compressional waves in rocks to 10 kilobars: 2. Journal of Geophysical Research, 66(7), 2199-2224.

Bowles, J. E., 1982. Foundation analysis and design " McGraw-Hill Book Company. NY.

Bridle, R., 2006. Plus/Minus refraction method applied to a 3D block. 2006 SEG Annual Meeting. Society of Exploration Geophysicists.

Christensen, N. I., 1996. Poisson's ratio and crustal seismology. Journal of Geophysical Research: Solid Earth, 101(B2), 3139-3156. 
Goldstein E., 1994. Expedited Site Characterization Geophysics: Geophysical Methods and Tools for Site Characterization. Prepared for the US Department of Energy by Lawrence Berkeley Laboratory, University of California. $124 \mathrm{p}$

Gharaibeh, A. 2003.Geological map of Umm Al Jimal. Natural Resources Authority. Umm Al Jimal map Sheet 3245-I, scale 1:50.000.

Hodgkinson, J., Brown, R. J., 2005. Refraction across an angular unconformity between nonparallel TI mediaRefraction, Angular Unconformity, TI Media. Geophysics, 70(2), D19-D28.

Khalil, M. H., Hanafy, S. M., 2008. Engineering applications of seismic refraction method: A field example at Wadi Wardan, Northeast Gulf of Suez, Sinai, Egypt. Journal of Applied Geophysics, 65(3-4), 132-141.

Khalil, M. H., Hanafy, S. M., 2016. Geotechnical parameters from seismic measurements: Two field examples from Egypt and Saudi Arabia. Journal of Environmental and Engineering Geophysics, 21(1), 13-28.

Lankston, R. W., 1989. The seismic refraction method; a viable tool for mapping shallow targets into the 1990's. Geophysics, 1542 .

Ólafsdóttir, E. Á., 2014. Multichannel Analysis of Surface Waves Methods for dispersion analysis of surface wave data, $70 \mathrm{pp}$.

Olafsdottir, E., Erlingsson, S., Bessason, B., 2018. Tool for analysis of multichannel analysis of surface waves (MASW) field data and evaluation of shear wave velocity profiles of soils. Canadian Geotechnical Journal, 55(2), 217-233.

Park, C., 2013. MASW for geotechnical site investigation. The Leading Edge, 32(6), 656-662.

Park, C. B., Miller, R. D., Xia, J., 1997. Multi-channel analysis of surface waves (MASW), a summary report of technical aspects, experimental results, and perspective. Kansas Geological Survey, 10-97 pp.

Park, Choon B., Miller, R. D., Xia, J., 1999. Multichannel analysis of surface waves. Geophysics, 64(3), 800808 .

Parry, R. G., 1977. Estimating bearing capacity in sand from SPT values. Journal of the Geotechnical Engineering Division, 103(9),1014-1019.

Patil, S. G., Dodagoudar, G. R., Menon, A., 2017. Active and passive surface wave techniques for site characterization at archaeological site of Gol-Gumbaz Vijayapura, South India. Indian Geotechnical Conference, IIT Guwahati, (December), 1-4 pp.

Pegah, E., Liu, H., 2016. Application of near-surface seismic refraction tomography and multichannel analysis of surface waves for geotechnical site characterizations: A case study. Engineering Geology, 208, 100-113.

Priya, B., Dodagoudar, G., 2017. Building 3D subsurface models and mapping depth to weathered rock in Chennai, south India. Journal of Geomatics, 11(2), 191-200.

Smadi, A., 1997. Geological map of Al Mafraq. Natural Resources Authority. Mafraq mapsheet 3254- IV, scale $1: 50.000$

Srinivas, G., Shankar, P., Kumar, K., Trupti, S., Kishore, P., Srinivas, K., Seshunarayana, T., 2018. Application of shallow seismic studies for civil engineering applications: A case study from Chennai city, Tamilnadu. The Journal of Indian Geophysical Union, 22 (3), 286-291.

Stümpel, H., Kähler, S., Meissner, R., Milkereit, B., 1984. The use of seismic shear waves and compressional waves for lithological problems of shallow sediments. Geophysical Prospecting, 32(4), 662-675.

Thomsen, L., 1986. Weak elastic anisotropy. Geophysics, 51(10), 1954-1966. 